\title{
Improving psychiatry training in the Foundation Programme
}

\author{
Jan Welch, ${ }^{1}$ Christine Bridge, ${ }^{1}$ David Firth, ${ }^{2}$ Alastair Forrest ${ }^{3}$
}

The Psychiatrist (2011), 35, 389-393, doi: 10.1192/pb.bp.111.034009

${ }^{1}$ South Thames Foundation School; ${ }^{2}$ Kent, Surrey and Sussex School of Psychiatry; ${ }^{3}$ London Deanery

Correspondence to Jan Welch (jan.welch@kcl.ac.uk)

First received 11 Jan 2011, final revision 15 Mar 2011, accepted 31 May 2011

\begin{abstract}
Aims and method We explored the views of foundation doctors on psychiatry placements to inform further post development. Following criticism of some South Thames Foundation School (STFS) psychiatry placements, STFS staff reviewed existing information on post quality and 21 foundation doctors in psychiatry posts took part in three focus groups.
\end{abstract}

Results Trainees are concerned about the general quality of posts (including supervision and induction); isolation of mental health trusts from 'acute' trusts; the professional position of junior psychiatrists; and responsibilities related to the Mental Health Act and risk assessment. Requirements for posts to address these issues have been developed and are now being implemented locally.

Clinical implications The conclusions are relevant to the quality management of foundation posts in mental health trusts, responses to the Collins Report (2010) and future recruitment into psychiatry.

Declarations of interest None.

\section{Background}

The Foundation Programme was established in the UK in 2005 as part of Modernising Medical Careers. It is a national 2-year generic training programme, usually consisting of three to four different placements in each of the first (F1) and second (F2) years, which forms the bridge between medical school and specialist/general practice training. It has a clearly defined curriculum, with competences that need to be achieved. Foundation placements in psychiatry were developed to enable foundation doctors to acquire relevant broad competences, as well as to encourage them to consider psychiatry as a career. Herzberg et $a l^{1}$ were optimistic about this opportunity, as F2 psychiatry posts would enable new graduates who might not otherwise do so to gain experience of psychiatry, with some being attracted to it as a career. Others have also suggested that increasing positive exposure to psychiatry during foundation years may assist recruitment: 'Several surveys have identified that the majority of people choose psychiatry as a career after graduation rather than during the undergraduate years'. ${ }^{2}$ By the end of their first year after qualification, doctors surveyed reported work experience as being a more important determinant of career choice when choosing psychiatry than with other specialties. $^{3}$

Brown \& Bhugra, ${ }^{4}$ reviewing foundation programme psychiatry posts, agreed and detailed the curricular content and educational support that make these experiences successful. Boyle et al described a successful foundation psychiatry placement, and portrayed the positive features fostering career intentions to pursue psychiatry: 'the professional and personal development provided within a one-to-one supervisory relationship, encouragement and support from consultants during MTAS, seeing patients responding positively to treatment and increasing direct involvement in patient care as the post progressed'..$^{5}$ (MTAS refers to the Medical Training Application Service, an online system that resulted in major problems in medical recruitment.) The Royal College of Psychiatrists, however, appears to have shifted from foundation as a focus for recruitment opportunity. When Brown \& Vassilas $^{6}$ reviewed the 'Sisyphean task' of recruiting psychiatrists, and the dramatic decline in the number of UK medical graduates choosing psychiatry, they looked to medical schools rather than the foundation years for solutions. Similarly, when Howard et $a l^{7}$ summarised College initiatives to tackle psychiatry's recruitment crisis, actions focused on medical schools and students.

Collins, reviewing the Foundation Programme, recently identified relevant areas. ${ }^{8}$ In recommendation 15 , the 'curriculum should be revised to give greater emphasis to the total patient, long-term conditions and the increasing role of community care. It should also reflect the changing ways of working, in particular the need for team-working skills within a multi-professional environment'. In a section on maldistribution of placements by specialty, recommendation 16 states that the 'successful completion of the Foundation Programme should normally require trainees to complete a rotation in a community placement, e.g. community paediatrics, general practice or psychiatry' ${ }^{8}$ 
Recommendation 17 is that the distribution of specialty posts must be reviewed to 'ensure broader based beginnings, to share the supervision of trainees among a wider number of supervisors and to ensure closer matching with current and future workforce requirements' as 'specialties with recruitment problems such as paediatrics and psychiatry are under-represented in terms of opportunities to experience these specialties at foundation level' ${ }^{8}$ Collins also commented on supervision, with Recommendation 24 stating that 'Methods must be developed to ensure that all health professionals and employers understand the objectives of the Foundation Programme, become quickly conversant with the prior clinical experience and level of competence of individual F1 and F2 trainees, and support the standard that no foundation doctor will be required to practise beyond their level of competence or without appropriate supervision'. ${ }^{\text {. }}$

\section{This study}

The South Thames Foundation School (STFS) is the largest foundation school in the UK, with more than 800 2-year programmes in 19 National Health Service (NHS) trusts within two deaneries: Kent, Surrey and Sussex (KSS) and London. The STFS encourages postgraduate exposure to psychiatry by providing $16 \mathrm{~F} 1$ psychiatry posts and $31 \mathrm{~F} 2$ psychiatry posts in South London and KSS, enabling 151 trainees a year to experience psychiatry in placements of up to 4 months in duration.

When two STFS local education providers were asked to reduce F1 programme numbers for 2009 and 2010 (as part of a national requirement), in both acute trusts the directors of medical education suggested removing psychiatry placements, as they felt that these were unpopular and did not provide good training

Given this salutary feedback, and anecdotal reports from other foundation schools suggesting that the problem was widespread, we reviewed existing local evidence on the quality of psychiatry placements. The results were conflicting, and so we decided to explore the issues in depth using focus groups ${ }^{9}$ with existing trainees in psychiatry from both deaneries, to obtain qualitative information about their experience and views and to inform future best practice.

\section{Method}

\section{Existing information about the quality of F1 and F2 psychiatry placements}

Existing information was collated from quality visits, trainee questionnaires and minutes of local faculty groups and local academic boards (based in acute trusts and each required to meet at least three times yearly and include discussion about local training posts). These sources are summarised below.

Minutes of local faculty groups and local academic boards and visit reports

These revealed largely negative evaluations of psychiatry posts, including overall unpopularity (and trainee avoidance) or judgements (by both F1 doctors and consultant psychiatrists) that posts provided little useful training.
The relative isolation of mental health trusts led to negative comments about the difficulties of maintaining medical skills through accessing on-call experience. There were criticisms of clinical and educational supervision, inappropriate responsibility and the duration and relevance of induction. A local Foundation Programme survey had given negative feedback for F1, with mixed results for F2. However, one local faculty group minute noted an $\mathrm{F} 1$ post as very popular and educationally useful, although trainees had experienced some initial anxiety.

Postgraduate Medical Training Board (PMETB) Survey 2009 All STFS trainees had been strongly encouraged to complete the annual PMETB online questionnaire. For F1 and F2 psychiatry in STFS the 2009 survey showed:

- scores above average for overall satisfaction for F1 psychiatry and below average for F2, and similar results for clinical supervision;

- scores above average for workload and European Working Time Regulations compliance;

- face-to-face handover scores very low for F1 and low for F2;

- hours of education (i.e. teaching time) scored highly for both F1 and F2, although F2 psychiatry had a lower than average adequate experience score;

- induction and educational supervision had an average score at F1 and F2.

\section{STFS psychiatry workshop}

All 47 foundation doctors in STFS psychiatry placements in June 2010 were invited to a half-day workshop. This group was chosen as it was felt that they would be able to give immediate feedback of their experience relevant to their current psychiatry placement, and permission could be obtained from their psychiatry supervisors to enable them to attend. We invited $12 \mathrm{~F} 1 \mathrm{~s}$ and $20 \mathrm{~F} 2 \mathrm{~s}$ from KSS trusts and $3 \mathrm{~F} 1 \mathrm{~s}$ and $12 \mathrm{~F} 2 \mathrm{~s}$ from London trusts. We received responses from 21 foundation doctors who wished to attend; 7 Fls and 5 F2s from KSS and 2 F1s and 7 F2s from London. A total of 11 doctors advised us that they could not attend due to prior commitments/pre-arranged leave/maternity leave; many had already discussed the issues with other trainees and two doctors gave feedback via email. In total, 15 doctors did not respond.

On the day of the focus groups the trainees were arranged into three groups each of seven foundation doctors; the groups were arranged so that F1 and F2 trainees and doctors from each deanery were as evenly distributed as possible. Discussion topics were allocated to three separate focus groups, ${ }^{9}$ each with a consultant psychiatrist educator (one foundation trainer, one head of school of psychiatry and one an associate postgraduate dean) as facilitator and an administrator to record the discussion. In one group a specialty trainee also attended and assisted the facilitator. Group A covered placement structure and facilities, group B induction, handover, legal aspects and team interaction, and group $\mathrm{C}$ teaching, curriculum and support. Three groups of seven foundation doctors rotated through each of A, B and C. Each focus group started with the facilitator giving a brief introduction about the scope of the session, after which the participants 
were encouraged to discuss the topic among themselves and make comments and suggestions. The facilitators then encouraged the group to explore and challenge these to produce generally applicable recommendations. Where themes or comments came up outside the topic areas, these were allowed to continue and develop, and were recorded with the rest of discussion so that there were overlapping themes across the three groups.

Discussion was lively and frank, with facilitators and observer impressed by the enthusiasm of contributors, the constructive nature of their comments and the clear need for action to be taken. Detailed transcripts were kept and subsequent summaries of each discussion prepared and examined for main themes within and across the focus groups. The summaries and theme identification were carried out by C.B. and J.W., not working in mental health, so that the preparation of the results was independent of the psychiatrists leading the focus groups. As the event was planned to identify and make changes in posts where they were unsatisfactory, the results were then expressed in the form of recommendations. The authors working in mental health (D.F. and A.F.) reviewed these for terminology and factual accuracy and contributed to the discussion.

\section{Results}

Some posts were obviously enjoyed and valued, whereas others gave aversive experiences of psychiatry (the latter directly relevant to recruitment). Across the experiences and posts clear difficulties and suggestions emerged (often across the groups); the latter are summarised below in the recommendations. Overall themes were the:

- general quality of posts (applying to any training post) including the availability and quality of clinical and educational supervision, internet access and timely and relevant induction;

- isolation of mental health trusts from 'acute' trusts, at which were sited foundation peers, induction, generic training as part of delivery of the Foundation Programme, and acute medical experience;

- professional position of junior psychiatrists (typically in multiprofessional teams with few doctors, with traditional handover and other practices, often working across multiple sites);

- responsibilities and processes of the Mental Health Act and risk assessment.

Themes were given sharper focus by the early stage of training of $\mathrm{F} 1$ and $\mathrm{F} 2$ doctors, with particular concern when a psychiatry placement was the first part of an F1 rotation. The newly qualified doctor would sometimes be located several miles away from the main site and their peers, in an unfamiliar environment without immediate opportunities to reinforce many skills learnt at medical school and acquire acute medical competences. They would be the only newly qualified doctor, working with a multiprofessional team whose roles may not be immediately obvious, as they have overlapping skills and responsibilities and seldom wear uniforms. Operational and educational arrangements commonly differ from those in acute trusts, for example much clinical supervision being provided by clinical psychologists or community psychiatric nurses rather than more senior doctors. The multiprofessional team may have considerable experience but little understanding of the Fl's training needs, and the situation would often be compounded by the absence of appropriate induction and supervision.

\section{Discussion}

Although noting the goals articulated for foundation training and the tensions between some of them, Collins ${ }^{8}$ comments supportively that 'The Foundation Programme facilitates the exposure of trainees to a broad range of medical specialties, including those experiencing recruitment difficulties' and that the 'generic, broad based experience of F1 and F2 should be retained'. Flexibility is also encouraged: ' $\mathrm{F} 2$ placements aligned as far as possible to the broad areas in which trainees hope to pursue their careers'. More trainee choice should be 'balanced by the future workforce needs of the NHS and its patients, and the requirement to meet all Foundation Programme generic competences'.

There are clearly tensions between these goals, which are felt and expressed by trainees. Collins notes 'Greater community experience will benefit all foundation trainees but may be unpopular especially with those who seek greater flexibility and choice' and that 'Under the current model there is the danger that trainees can become disengaged and de-motivated if the placements allocated to them - or at least some of them - are not broadly aligned to their choice. Nevertheless, the Evaluation Panel heard from a number of trainees who were initially dissatisfied about being allocated placements in the community but who went on to enjoy and benefit from this experience. ${ }^{8}$

In our study local background information revealed a mixed picture, with some posts providing excellent experience but others falling far short. Some adverse views from acute trusts may have reflected bias against psychiatry or the need to cover acute rotas, but the focus groups' discussion confirmed these extremes. They also identified common themes to suggest changes required to provide optimal training experiences.

There are clearly major differences between the F1 and F2 years. We feel that F1 doctors should not be doing psychiatry on call (other than 'shadowing'), but ideally should do medical on call in their acute hospital even when in a psychiatry placement. They should be able to attend teaching sessions and social events at the acute trust, and teaching there could usefully include psychiatry topics. Such arrangements minimise isolation, as foundation doctors would maintain linkages with their peer group in the acute hospital. Trainees could also keep up with their peers in acquiring acute medical competences, so would not appear to be behind when starting their next acute placement. Current isolation will also be reduced if, in line with Collins' recommendations, more training posts are developed within community settings such as psychiatry.

The Mental Health Act responsibilities of F2 doctors emerged strongly in the focus groups. Many F2 posts were developed from former senior house officer posts during 2006/2007 training reconfiguration. The F2 doctors are therefore often part of psychiatry duty doctor rotas, 
together with core psychiatry trainees. The duty doctor customarily has particular responsibility to assess voluntary in-patients for detention under the Mental Health Act, by signing Section 5(2). As an action under the law this requires knowledge of the Act. This is an appropriate activity for foundation doctors to undertake provided that they are adequately trained, including supervised practice until assessed as competent. (Specific arrangements would need to be tied to duty rota documentation, designating the nominated deputy legally.)

Both F1 and F2 trainees agreed similarly about responsibility for carrying out and documenting risk assessment, a role often assigned automatically. Although ward-based risk assessment may be technically done under supervision (in that others are physically present on the ward) trainees may feel 'dumped upon', with no one taking specific responsibility for guiding them. Instead, risk assessment should be viewed as another specific responsibility with potential legal consequences, for which training and competency assessment should be provided and formally confirmed before trainees carry out these duties. Trainee's views on handover particularly demonstrate differences between 'acute' trusts and many acute admission units in mental health trusts. A good-quality 'next-day' handover in, for example, neurosurgery would review all acute referrals and admissions (including acute management, initial rehabilitation and discharge planning) and involve doctors and other staff at all levels often with space allocated for teaching. Educational governance looks for these features. This model may not be suited to community mental health teams or even to acute psychiatric admission units, but emphasises that foundation trainees not only enter the culture of mental health, but also bring knowledge of other medical cultures with them.

The desire of trainees to know about the kinds of psychiatry post available came across strongly. For example, some sought an old age psychiatry post so they could maintain their medical skills, whereas others were more interested in general adult psychiatry in order to experience psychopathology, psychiatric assessment and treatments and test out whether psychiatry was the right career choice for them. Although we believe that medical schools could do more to prepare students for work in psychiatry, as regards both curricular time and clinical exposure, we also feel that all foundation psychiatry posts should be well structured and supervised. We are reviewing our recommendations with the KSS and London schools of psychiatry, and will implement them within STFS, and monitor their impact over the coming year. We believe that ensuring that foundation psychiatry posts meet these recommendations will do much to encourage new doctors to develop a psychological understanding of patients, achieve relevant competences and consider psychiatry as a career.

\section{Outcomes from the focus group themes: recommendations for foundation posts in psychiatry}

Structure of training and facilities

Foundation posts in psychiatry should:

- be of 4 months duration (although lengthy tasters, for example 1 month, would be acceptable if appropriately supervised and structured). Shorter placements were proscribed in the Collins evaluation, whereas 6-month placements would mean that only two specialties could be sampled during the year;

- maintain links with the acute hospital site (e.g. in a surgical/medical on-call rota) and provide protected time there to allow interaction with other foundation colleagues;

- provide breadth of experience, including both in-patients and out-patients as well as ward/clinic/community experience;

- provide details of the type of psychiatry placement before allocation;

- ensure that nurses and other staff members are aware of F1 and F2 roles and responsibilities and what can be expected of them (such as prescribing and the Mental Health Act);

- give immediate access to trust information technology systems and bleeps or an appropriate alternative.

\section{Induction}

Psychiatry induction should include time to learn about the wards' operational arrangements and the patients, as well as focusing on:

- psychiatry team structure, how this works in the hospital, and the on-call system;

- clinical support - whom to contact, when, about what;

- local community services and boundaries - which services are available and whom to contact about these;

- post content, and the competences to be gained;

- immediate actions under the Mental Health Act; risk assessment: responsibility, forms (how to complete), practical use and legal and governance consequences;

- initial training and supervision: on assessment of patients (e.g. dementia, suicide assessments, risk assessment), the Mental Health Act, pharmacology, and capacity.

\section{Supervision}

Foundation doctors must be appropriately supervised at all times, initially by a more senior colleague when seeing patients, until they gain confidence and can feed back to a consultant. Trainees must have regular timetabled contact with the consultant (e.g. meeting the consultant and a registrar alternating weekly) to bring a topic or cases for discussion. Foundation doctors should only sign Section 5(2) forms (or carry out any other Mental Health Act responsibility) or carry out risk assessment (ward or community based) once shown to be competent (e.g. by supervisors confirming specific supervised experience and discussion in personal supervision) and therefore not during a specified initial period of the attachment.

\section{Teaching}

Formal teaching should include:

- protected foundation teaching at the main acute site;

- psychiatry-specific teaching within the placement;

and also include where possible:

- simulation training; 
- time set aside to share cases and experiences with colleagues;

- teaching others.

Handover

Regular multidisciplinary handovers would be helpful.

\section{Implications}

Foundation placements in psychiatry can deliver important components of the foundation curriculum, and remain an early opportunity to present the attractions of a career in psychiatry to a large cohort of doctors. They need to maintain the quality to which the Royal College of Psychiatrists aspired when this system was introduced, and actively incorporate the training provision, educational support and legal protection of doctors in the foundation years. The vigorous input from our focus group participants provided valuable measures of the quality of these placements, for debate and enactment.

\section{About the authors}

Jan Welch is director of the South Thames Foundation School, Guy's Hospital, London. Christine Bridge is a manager of the South Thames Foundation School, Royal Sussex County Hospital, Eastern Road, Brighton. David Firth is a consultant psychiatrist and head of the Kent, Surrey and Sussex School of Psychiatry. Alastair Forrest is a retired consultant psychiatrist and a liaison dean at London Deanery.

\section{Acknowledgements}

We thank Charlotte Wilson-Jones for facilitating one of the workshops, and the trainees who participated.

\section{References}

1 Herzberg J, Forrest A and Heard S. Modernising medical careers: an opportunity for psychiatry? Psychiatr Bull 2004; 28: 233-4.

2 Brockington IF, Mumford DB. Recruitment into psychiatry. Br J Psychiatry 2002; 180: 307-12.

3 Goldacre MJ, Laxton L, Lambert TW. Medical graduates early career choices of specialty and their eventual specialty destinations: UK prospective cohort studies. BMJ 2010; 340: 6 July (Epub ahead of print).

4 Brown N, Bhugra D. Modernising medical careers, the Foundation Programme and psychiatry. Psychiatr Bull 2005; 29: 204-6.

5 Boyle AM, Chaloner DA, Millward T, Rao V, Messer C. Recruitment from foundation year 2 posts into specialty training: a potential success story? Psychiatr Bull 2009; 33: 306-8.

6 Brown N, Vassilas CA, Oakley C. Recruiting psychiatrists - a Sisyphean task? Psychiatr Bull 2009; 33: 390-2.

7 Howard R, Oakley C, Harrison J. Tackling psychiatry's recruitment crisis head on. Royal College of Psychiatrists. RCPsych News 2008; November (http://www.rcpsych.ac.uk/member/rcpsychnews/november2008.aspx).

8 Collins J. Foundation for Excellence. An Evaluation of the Foundation Programme. Medical Education England, 2010.

9 Kitzinger J. Qualitative research: introducing focus groups. BMJ 1995 311: 299 . 